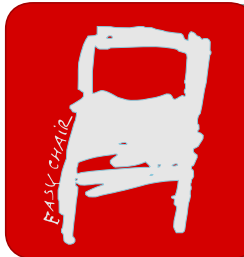

EPiC Series in Health Sciences

Volume 3, 2019, Pages 40-45

CAOS 2019. The 19th Annual Meeting of the International Society for Computer Assisted Orthopaedic Surgery

\title{
One and Two Year Postoperative Patient Repoted Outcomes of Robotic-Assisted Total Knee Arthroplasty
}

\author{
Christopher L Blum ${ }^{1}$, MD, Christopher Plaskos ${ }^{2}$, PHD, Adil Hussein ${ }^{3}$ MS and Jan A Koenig ${ }^{4}$, MD \\ NYU Winthrop University Hospital, 259 1st St, Mineola, NY 11501, US \\ jkoenigmd@orthoexcellence.com
}

\begin{abstract}
Total knee arthroplasty is a successful procedure. However, there is still area for improvement as up to $15-20 \%$ of patients remain unsatisfied. Robotic-assisted surgery (RAS) may improve patient outcomes by providing a reproducible way of obtaining neutral mechanical alignment of the limb, which has been shown to reduce early revisions and correlate with patient reported outcomes after surgery.

We prospectively enrolled 106 patients undergoing robotic-assisted TKA by a single surgeon performing a measured-resection femur-first technique using the OMNIBotic system. Patients completed a KOOS and New Knee Society Score (KSS) pre-operatively and at 3, 6, 12, and 24 months (M) postoperatively. Changes in the five KOOS sub-scales were compared to available literature data from the FORCE - TJR cohort, as well as to individual studies reporting on conventional and computer-assisted TKA.

When compared to FORCE-TJR 6-month (M) and 2-year (Y) data, the RAS cohort had significantly higher improvements at $6 \mathrm{M}$ for pain $(40.5$ vs. $31.1, \mathrm{p}<.001)$ and at $2 \mathrm{Y}$ for all five KOOS sub-scores. The larger improvement was due to the RAS cohort having lower baseline KOOS scores than the FORCE-TJR cohort, except for the Sports-Recreation sub-score, which was similar preoperatively but significantly higher post-operatively for the robotic cohort. Rates of dissatisfaction with knee pain level and function using the KSS after RAS were $3.0 \%, 1.0 \%$, and $2.7 \%$ at 6,12 , and $24 \mathrm{M}$ postoperatively, respectively.

Despite having poorer joint function and higher pain pre-operatively, robotic-assisted TKA patients achieved excellent self-reported outcomes, with significantly higher levels of improvement through two years post-surgery when compared with large national cohort studies. Further controlled clinical studies are warranted to determine if these results translate to other groups of surgeons, centers and patients.
\end{abstract}

\section{Introduction}

Total knee arthroplasty will continue to grow in incidence in the coming years, yet patient satisfaction with the procedure is still variable. With current literature showing satisfaction of around $80-85 \%$ (1-4), there is still significant room for improvement. Prior studies have shown that correcting varus/valgus alignment within 3 degrees of neutral has improved outcomes for patients in terms of 
early revisions and functional outcomes score (5-8). The multitude of deformities that can be present at time of surgery also add to the challenge of obtaining consistent results (9). As the demand for this procedure grows, we must continue to work towards better outcomes for our patients.

A potential solution to this problem is augmenting the surgical endeavor in a way that allows the surgeon to be more precise with his or her instrumentation, and obtain real time feedback of intraoperative decisions $(7,10-12)$. This is where robotics and computer assisted surgery may provide a significant benefit. The early results of this technology have been mixed when compared to conventional total knee arthroplasty, with increased operative time, excellent reproducible alignment, but overall little change in patient outcomes (13-15). Yet, the field has continued to expand and improve, with the goal of making a highly functional and reproducible total knee procedure without significantly increasing cost or surgical time (16-20). The OMNI robotic total knee arthroplasty system aims to address these issues and hopes to improve long-term patient outcomes.

We report on the three and six month and one and two year follow up in an ongoing singlesurgeon study using the OMNIBotic total knee arthroplasty (TKA) system. Post-operative patient reported functional outcomes scores are compared to prior scores in the literature on computerassisted and conventional TKA.

\section{Methods}

We prospectively evaluated 106 patients who underwent total knee arthroplasty using the OMNIBotic Computer Assisted Total Knee System over a 2-year period $(11,12)$. The system was used in a measured-resection femur-first technique and included use of a miniature bone-mounted robotic cutting-guide. The system acquires hundreds of datapoints using real-time three-dimensional mapping of the articular surface $(11,12)$. Patients underwent primary knee replacement with a standard medial parapatellar incision using the OMNI Apex CR/Ultra-Congruent total knee system. The patients had a standard post-operative protocol which consisted of weight bearing as tolerated and physical therapy. The post-operative outcomes were evaluated using the Knee injury and Osteoarthritis Outcome Score (KOOS), New Knee Society Score (KSS), and Veterans RAND -12 (VR-12) outcome measures. The patients were evaluated prior to the surgery and at 3,6,12 and 24 months post-operatively. Changes in the five KOOS subscales were compared to available literature data from FORCE - TJR $(21,22)$, a large, prospective, national cohort of TJR patients, as well as to individual studies (23-25) reporting on conventional and computer assisted TKA patient outcomes. A two tailed t-test was used to identify statistically significant differences between the groups. Variance in PROM score improvements were assumed to be equal to the robotic cohort when variance values were not available in the literature data. We also evaluated post-operative patient satisfaction with their procedure.

\section{Results}

Patients who underwent Robotic assisted surgery (RAS) for TKA reported significantly improved outcomes at 3, 6, 12 and 24 months (M) from pre-operative baseline values (tables 1 and 2). The improvement in KOOS subscales were generally higher for RAS when compared to conventional total knee arthroplasty (Conv.) at 3M for pain (32.6 RAS vs 19.7 Conv., $\mathrm{p}-$ value $<0.001$ ), Symptoms (27.1 RAS vs 7.0 Conv., p-value <0.001), ADL (32.9 RAS vs 20.9 Conv., p-value $<0.001$ ), SportsRec (20.0 RAS vs 7.6 Conv., p-value $=0.02$ ), and QOL (40.9 RAS vs 27.8 Conv., -value $=$ 0.01 ) (Table 1). The improvement in KOOS subscales continued to be higher for RAS when compared to Conv. out to the $2 \mathrm{Y}$ mark as well. For pain (45.9 RAS vs 38.2 Conv., $\mathrm{p}-$ value $=0.001$ ), Symptoms (39.6 RAS vs 32.1 Conv., p-value $=0.002)$, ADL (41.7 RAS vs 31.1, p-value $<0.001$ ), 
SportsRec (44.4 RAS vs 33.9 Conv., p-value $=0.005$ ), and QOL (56.5 RAS vs 42.8 Conv., p-value $<0.001$ ) (Table 1).

When compared to the FORCE-TJR registry cohort 6M and 2-year (Y) data, the RAS cohort had significantly higher improvements at $6 \mathrm{M}$ for pain and at $2 \mathrm{Y}$ for all five sub-scores (table 1 ). The larger improvement in the RAS group was mainly due to the RAS cohort having lower baseline KOOS scores than the FORCE-TJR group, except for the Sports and Recreation sub-score, where the RAS group had a similar pre-operative but significantly higher post-operative score. Improvements in 2011 KSS patient satisfaction and functional scores at $6 \mathrm{M}$ were 11 and 10 points greater than those reported for conventional TKA (p-values of $<0.001$ for both subgroups). A mean of $31 \mathrm{pts}$ for the Patient Satisfaction score indicates that on average patients were 'Satisfied' with their knee function and pain level. Rates of dissatisfaction with knee pain level and function using the KSS after RAS were $3.0 \%, 1.0 \%$, and $2.7 \%$ at 6,12 , and $24 \mathrm{M}$ postoperatively, respectively.

\section{Discussion}

Robotic assisted TKA provides a way to reproducibly obtain a neutral alignment of the lower limb and aims to improve patient outcomes $(10,15,17)$. The results showed increasing and sustained improvements in patient reported outcome scores and in all KOOS subscales through the first two years with use of a robotic TKA system. It also appears that patients were more satisfied after robotic knee arthroplasty when compared to prior total knee surgery results seen in the literature $(4,26,27)$. This information shows how robotic assisted TKA may help to improve patient outcomes in both the short and mid-term.

In terms of study limitations, there is relatively short follow up of only 2 years. However, studies have shown that most of the expected improvement in pain and function following TKA can be seen at 6 months postoperatively, with moderate additional improvement up to the 2 year timepoint (28). Additionally, no control cohort from the same surgeon or same institution is included for comparison. The senior surgeon author who performed these cases (JAK) however only performs robotic knee replacement surgery and does not perform conventional (manual) surgery, which makes a conventional same-surgeon control cohort difficult to obtain. A third limitation is that a systematic review of the literature was not performed for comparison data. We did however compare our data with that of a large national cohort that is believed to be largely representative of the standard of care for TKA across the United States (20). Finally, we did have a drop out of patients within the study, with 75 patients reporting outcomes at $2 \mathrm{Y}$, down from 104 patients at the $3 \mathrm{M}$ mark. However, we are still collecting final data, and expect the RAS $2.7 \%$ KSS dissatisfaction rate to drop even lower as we finalize our $2 \mathrm{Y}$ follow up.

\section{Conclusion}

Robotic assisted TKA shows excellent results in terms of patient reported outcomes through 2 years post-operatively in our study. It appears that these patients have improved outcome scores when compared to conventional total knee arthroplasty during this period. Further long-term data needs to be considered to draw major conclusions, however, robotic assisted TKA provides a promising avenue in the quest for continued patient satisfaction and patient outcomes for total knee arthroplasty, with 2-year data now available. 
One and Two Year Postoperative Patient Reported Outcomes of Robotic-Assisted ... C. Blum et al.

Table 1 - KOOS subscale scores for robotics assisted total knee arthroplasty (RAS -TKA) and literature data $\left({ }^{*} \mathrm{p}<0.05\right)$

\begin{tabular}{|c|c|c|c|c|c|c|c|c|c|c|c|c|c|c|c|c|c|c|c|c|}
\hline & \multicolumn{9}{|c|}{ RAS-TKA } & \multicolumn{2}{|c|}{$\begin{array}{c}\text { Gøthesen } \\
2014 \\
{[21]}\end{array}$} & & & $\begin{array}{l}\text { Roos } \\
2003 \\
{[23]}\end{array}$ & & $\begin{array}{c}\text { Li } \\
2017 \\
{[19]}\end{array}$ & & $\begin{array}{l}\text { Lyman } \\
2018 \\
{[20]}\end{array}$ & & \\
\hline & Pre-Op & $3 \mathrm{M}$ & $6 \mathrm{M}$ & $1 Y$ & $2 Y$ & $\begin{array}{c}\Delta \text { Pre-op } \\
\& 3 \mathrm{M}\end{array}$ & $\begin{array}{c}\Delta \text { Pre- } \\
\text { op \& } \\
6 \mathrm{M}\end{array}$ & $\begin{array}{c}\Delta \text { Pre- } \\
\text { op \& } \\
1 \gamma\end{array}$ & $\begin{array}{c}\Delta \text { Pre- } \\
\text { op \& } \\
2 Y\end{array}$ & $\begin{array}{r}\Delta \mathrm{PrE} \\
\& 3\end{array}$ & & $\begin{array}{c}\text { P value } \\
3 \mathrm{M}\end{array}$ & $\begin{array}{c}\text { Pvalue } \\
3 \mathrm{M}\end{array}$ & $\begin{array}{c}\triangle \text { Pre-op } \\
\& 6 \mathrm{M}\end{array}$ & $\begin{array}{c}\text { P value } \\
6 \mathrm{M}\end{array}$ & $\begin{array}{l}\Delta \text { Pre- } \\
\text { op } \\
\& 6 \mathrm{M}\end{array}$ & $\begin{array}{c}\text { P value } \\
6 \mathrm{M}\end{array}$ & $\begin{array}{c}\Delta \text { Pre- } \\
\text { op } \\
\& 2 Y\end{array}$ & $\begin{array}{l}P \text { value } \\
1 Y-2 Y\end{array}$ & $\begin{array}{l}\text { P value } \\
2 Y-2 Y\end{array}$ \\
\hline $\begin{array}{c}\text { KOOS } \\
\text { Subscale }\end{array}$ & $n=106$ & $n=104$ & $\mathrm{n}=101$ & $\mathrm{n}=101$ & $n=74$ & & & & & $\begin{array}{l}\text { Conv. } \\
n=90\end{array}$ & $\begin{array}{l}\text { CAS } \\
\mathrm{n}=92\end{array}$ & $\begin{array}{c}\Delta \text { RRAS } \\
\text { vs } \\
\Delta \text { Conv. }\end{array}$ & $\begin{array}{c}\Delta R A S \\
\text { vs } \\
\Delta C A S .\end{array}$ & $\begin{array}{l}\text { Conv. } \\
n=97\end{array}$ & $\begin{array}{c}\Delta R A S \\
\text { vs } \\
\Delta \text { Conv. }\end{array}$ & $\begin{array}{l}\text { Reg. } \\
n=2,792\end{array}$ & $\begin{array}{c}\Delta \text { RAS } \\
\text { vs } \\
\Delta \text { Reg }\end{array}$ & $\begin{array}{c}\text { Reg. } \\
n=1114\end{array}$ & $\begin{array}{l}\Delta \text { RAS } \\
\text { vs } \\
\Delta \operatorname{Reg}\end{array}$ & $\begin{array}{c}\triangle R A S \\
\text { vs } \\
\Delta R e g\end{array}$ \\
\hline Pain & 42.6 & 75.3 & 82.8 & 85.5 & 86.7 & 32.6 & 40.5 & 43.8 & 45.9 & 19.7 & 27.4 & $<.001^{*}$ & 0.06 & 41 & 0.86 & 31.1 & $<0.001^{*}$ & 38.2 & $0.002^{*}$ & $0.001^{*}$ \\
\hline Symptoms & 45.2 & 72.4 & 78.0 & 80.1 & 83.4 & 27.1 & 32.8 & 35.5 & 39.6 & 7.0 & 13.1 & $<.001^{*}$ & $<.001^{*}$ & 25 & $0.01^{*}$ & - & - & 32.1 & 0.087 & $0.002^{*}$ \\
\hline ADL & 45.3 & 78.6 & 83.8 & 86.1 & 86.1 & 32.9 & 38.5 & 41.5 & 41.7 & 20.9 & 26.3 & $<.001^{*}$ & $0.01^{*}$ & 36 & 0.38 & - & - & 31.1 & $<.001^{*}$ & $<.001^{*}$ \\
\hline SportRec & 20.5 & 40.7 & 49.7 & 59.7 & 64.2 & 20.0 & 29.0 & 39.0 & 44.4 & 7.6 & 21.1 & $0.02^{*}$ & 0.84 & 32 & 0.57 & - & - & 33.9 & 0.133 & $0.005^{*}$ \\
\hline Q.OL & 21.1 & 62.2 & 67.5 & 72.4 & 76.5 & 40.9 & 46.6 & 52.2 & 56.5 & 27.8 & 35.0 & $0.01^{*}$ & $0.01^{*}$ & 40 & $0.01^{*}$ & - & - & 42.8 & $<.001^{*}$ & $<.001^{*}$ \\
\hline
\end{tabular}

Months (M), Years (Y), Conventional TKA (Conv.), Computer-assisted TKA (CAS), Registry Data (REG), Robotics Assisted Total Knee Replacement (RAS), Knee Injury and Osteoarthritis Outcome Score (KOOS)

Table 2 - 2011 Knee Society Scores (KSS) for RAS-TKA and literature data $(* \mathrm{p}<0.05)$

\begin{tabular}{|c|c|c|c|c|c|c|c|c|c|c|c|}
\hline & & & & & & RAS-TKA & & Uefuji 20 & 5 (Conv & KA) [26] & \\
\hline 2011 KSS & $\begin{array}{l}\text { Pre-Op } \\
n=106\end{array}$ & $\begin{array}{c}3 M \\
n=104\end{array}$ & $\begin{array}{c}6 \mathrm{M} \\
\mathrm{n}=101\end{array}$ & $\begin{array}{c}1 Y \\
n=101\end{array}$ & $2 Y$ & $\begin{array}{c}\Delta \text { Pre- } \\
\text { op \& 3M } \\
n=104\end{array}$ & $\begin{array}{c}\Delta \text { Pre- } \\
\text { op \& } 6 \mathrm{M} \\
n=101\end{array}$ & $\begin{array}{l}\text { Pre-Op } \\
n=52\end{array}$ & $\begin{array}{l}6 \mathrm{M} \\
\mathrm{n}=52\end{array}$ & $\begin{array}{l}\Delta \text { Pre- } \\
\text { op \& } \\
6 \mathrm{M}\end{array}$ & $\begin{array}{l}\begin{array}{c}\text { P value } \\
6 \mathrm{M}\end{array} \\
\Delta \text { RAS vs } \\
\Delta \text { Conv. }\end{array}$ \\
\hline $\begin{array}{l}\text { Expectation (15 } \\
\text { pts) }\end{array}$ & 14.0 & 10.2 & 10.2 & 10.5 & 10.1 & & & 12 & 10 & - & - \\
\hline $\begin{array}{l}\text { Satisfaction (40 } \\
\text { pts) }\end{array}$ & 12.1 & 29.4 & 31.2 & 32.3 & 32.8 & 17.3 & 19.20 & 14 & 22 & 8 & $<.001^{*}$ \\
\hline $\begin{array}{l}\text { Functional (100 } \\
\text { pts) }\end{array}$ & 36.7 & 62.2 & 67.3 & 70.5 & 71.5 & 25.3 & 30.5 & 44 & 64 & 20 & $<.001^{*}$ \\
\hline Objective & 22.0 & 72.9 & 73.8 & 74.7 & 74.7 & 50.9 & 51.8 & - & - & - & - \\
\hline
\end{tabular}

Months (M), Years (Y), Conventional TKA (Conv.), Computer-assisted TKA (CAS), Registry Data (REG), Robotics Assisted Total Knee Replacement (RAS), Knee Society Score (KSS)

\section{References}

1. Bourne RB, Chesworth B, Davis A, Mahomed N, Charron K. Comparing patient outcomes after THA and TKA: is there a difference? Clin Orthop Relat Res. 2010;468(2):542-6.

2. Losina E, Thornhill TS, Rome BN, Wright J, Katz JN. The dramatic increase in total knee replacement utilization rates in the United States cannot be fully explained by growth in population size and the obesity epidemic. J Bone Joint Surg Am. 2012;94(3):201-7. 
3. Robertsson O, Dunbar M, Pehrsson T, Knutson K, Lidgren L. Patient satisfaction after knee arthroplasty: a report on 27,372 knees operated on between 1981 and 1995 in Sweden. Acta Orthop Scand. 2000;71(3):262-7.

4. Gunaratne R, Pratt DN, Banda J, Fick DP, Khan RJK, Robertson BW. Patient Dissatisfaction Following Total Knee Arthroplasty: A Systematic Review of the Literature. J Arthroplasty. 2017;32(12):3854-60.

5. Meneghini RM, Grant TW, Ishmael MK, Ziemba-Davis M. Leaving Residual Varus Alignment After Total Knee Arthroplasty Does Not Improve Patient Outcomes. J Arthroplasty. 2017;32(9S):S171-S6.

6. Nakajima A, Sonobe M, Akatsu Y, Aoki Y, Takahashi H, Suguro T, et al. Association between limb alignment and patient-reported outcomes after total knee arthroplasty using an implant that reproduces anatomical geometry. J Orthop Surg Res. 2018;13(1):320.

7. Sparmann M, Wolke B, Czupalla H, Banzer D, Zink A. Positioning of total knee arthroplasty with and without navigation support. A prospective, randomised study. J Bone Joint Surg Br. 2003;85(6):830-5.

8. Teeny SM, Krackow KA, Hungerford DS, Jones M. Primary total knee arthroplasty in patients with severe varus deformity. A comparative study. Clin Orthop Relat Res. 1991(273):19-31.

9. Almaawi AM, Hutt JRB, Masse V, Lavigne M, Vendittoli PA. The Impact of Mechanical and Restricted Kinematic Alignment on Knee Anatomy in Total Knee Arthroplasty. J Arthroplasty. 2017;32(7):2133-40.

10. Decking J, Theis C, Achenbach T, Roth E, Nafe B, Eckardt A. Robotic total knee arthroplasty: the accuracy of CT-based component placement. Acta Orthop Scand. 2004;75(5):573-9.

11. DeClaire DJ. OMNIBotics Surgery featuring Active Spacer ${ }^{\mathrm{TM}}$ Technology, Presentation and Surgery featured at ICJR 2018 Vail Conference2018.

12. Koenig JA. Robotic-Assisted Total Knee Replacement: A Surgical Technique Video2016.

13. Courtney PM, Lee GC. Early Outcomes of Kinematic Alignment in Primary Total Knee Arthroplasty: A Meta-Analysis of the Literature. J Arthroplasty. 2017;32(6):2028-32 e1.

14. Yim JH, Song EK, Khan MS, Sun ZH, Seon JK. A comparison of classical and anatomical total knee alignment methods in robotic total knee arthroplasty: classical and anatomical knee alignment methods in TKA. J Arthroplasty. 2013;28(6):932-7.

15. Cho KJ, Seon JK, Jang WY, Park CG, Song EK. Robotic versus conventional primary total knee arthroplasty: clinical and radiological long-term results with a minimum follow-up of ten years. Int Orthop. 2018.

16. Pearle AD, van der List JP, Lee L, Coon TM, Borus TA, Roche MW. Survivorship and patient satisfaction of robotic-assisted medial unicompartmental knee arthroplasty at a minimum twoyear follow-up. Knee. 2017;24(2):419-28.

17. Jacofsky DJ, Allen M. Robotics in Arthroplasty: A Comprehensive Review. J Arthroplasty. 2016;31(10):2353-63.

18. Moschetti WE, Konopka JF, Rubash HE, Genuario JW. Can Robot-Assisted Unicompartmental Knee Arthroplasty Be Cost-Effective? A Markov Decision Analysis. J Arthroplasty. 2016;31(4):759-65.

19. J.A. Koenig, C. Plaskos. Influence Of Pre-Operative Deformity On Surgical Accuracy And Time In Robotic-Assisted Tka. Orthopaedic Proceedings [Internet]. 2013; 95-B(SUPP_28).

$20 . \quad$ J.A. Koenig, E.M. Suero, C. Plaskos. Surgical Accuracy And Efficiency Of ComputerNavigated Tka With A Robotic Cutting Guide - Report On The First 100 Cases. Orthopaedic Proceedings [Internet]. 2012; 94-B(SUPP_XLIV).

21. Li W, Ayers DC, Lewis CG, Bowen TR, Allison JJ, Franklin PD. Functional Gain and Pain Relief After Total Joint Replacement According to Obesity Status. J Bone Joint Surg Am. 2017;99(14):1183-9. 
22. Lyman S, Lee YY, Franklin PD, Li W, Cross MB, Padgett DE. Validation of the KOOS, JR: A Short-form Knee Arthroplasty Outcomes Survey. Clin Orthop Relat Res. 2016;474(6):1461-71. 23. Gothesen O, Espehaug B, Havelin LI, Petursson G, Hallan G, Strom E, et al. Functional outcome and alignment in computer-assisted and conventionally operated total knee replacements: a multicentre parallel-group randomised controlled trial. Bone Joint J. 2014;96-B(5):609-18.

24. Kuroda Y, Matsumoto T, Takayama K, Ishida K, Kuroda R, Kurosaka M. Subjective evaluation before and after total knee arthroplasty using the 2011 Knee Society Score. Knee. 2016;23(6):964-7.

25. Roos EM, Toksvig-Larsen S. Knee injury and Osteoarthritis Outcome Score (KOOS) validation and comparison to the WOMAC in total knee replacement. Health Qual Life Outcomes. $2003 ; 1: 17$.

26. Bourne RB, Chesworth BM, Davis AM, Mahomed NN, Charron KD. Patient satisfaction after total knee arthroplasty: who is satisfied and who is not? Clin Orthop Relat Res. 2010;468(1):5763.

27. Baker PN, van der Meulen JH, Lewsey J, Gregg PJ, National Joint Registry for E, Wales. The role of pain and function in determining patient satisfaction after total knee replacement. Data from the National Joint Registry for England and Wales. J Bone Joint Surg Br. 2007;89(7):893-900. 28. Nerhus TK, Heir S, Thornes E, Madsen JE, Ekeland A. Time-dependent improvement in functional outcome following LCS rotating platform knee replacement. Acta Orthop. 2010;81(6):72732 . 